\title{
MUDANÇAS NO USO DA TERRA A PARTIR DA EXPANSÃO DO CULTIVO DA CANA-DE-AÇÚCAR NA REGIÃO OESTE DO ESTADO DE SÃO PAULO
}

http://dx.doi.org/10.21527/2237-6453.2021.55.10754

Recebido em: 15/5/2020

Aceito em: $15 / 4 / 2021$

Ivana Sayuri Kodama, ${ }^{1}$ Wagner Luiz Lourenzani²

\section{RESUMO}

O Brasil é o maior produtor de cana-de-açúcar e apresenta elevada competitividade na produção do etanol. O lançamento dos veículos flex fuel, em 2003, propiciou uma nova fase de expansão do cultivo dessa cultura, principalmente no Estado de São Paulo. Esse processo, contudo, não ocorreu de forma homogênea em todo o território estadual, sendo muito mais expressivo na região Oeste Paulista. Nesse contexto, este estudo tem por objetivo analisar as mudanças no uso da terra na região Oeste Paulista, no período entre 2003 e 2018, provocadas pela expansão do cultivo de cana-de-açúcar. Para tanto, utiliza-se o modelo Shift-Share, que, por meio da decomposição da variação das áreas, possibilita calcular os efeitos escala e substituição das principais atividades em análise. Os resultados sugerem conflito no uso da terra entre a cana-de-açúcar e as culturas já instaladas, principalmente a soja, borracha e amendoim e que a expansão canavieira na região foi impulsionada, principalmente, pela substituição de culturas como o milho, frutas, feijão, café, trigo e arroz, e também pela incorporação de áreas de pastagens, consequentemente, da atividade pecuária bovina.

Palavras-chave: Cana-de-açúcar. Expansão. Shift-Share. Uso da terra.

\section{LAND USE CHANGES FROM THE SUGARCANE EXPANSION IN THE WESTERN REGION OF SÃO PAULO STATE}

\section{ABSTRACT}

Brazil is the largest sugarcane producer and is highly competitive in ethanol production. The launch of flex fuel vehicles, in 2003, provided a new phase of expansion of this cultivation, mainly in the state of São Paulo. However, this process did not occur homogeneously throughout the state, being much more expressive in the western region. In this context, this study aims to analyze the changes in land use in the West Paulista region, between 2003 and 2018 , caused by the expansion of sugarcane cultivation. For this purpose, the shift-share model was used, which, by decomposing the variation of areas, makes it possible to calculate the scale and substitution effects of the main activities under analysis. The results showed a conflict in land use between sugarcane and crops already installed, mainly soy, rubber and peanuts and that the expansion of sugarcane in the region was driven mainly by the replacement of crops such as corn, fruits, beans, coffee, wheat and rice, and also for the incorporation of pasture areas, consequently, of the cattle raising activity.

Keywords: Sugarcane. Expansion. Shift-Share. Land use.

\footnotetext{
${ }^{1}$ Autora correspondente. Universidade Estadual Paulista “Júlio de Mesquita Filho" (Unesp). Faculdade de Ciências e Engenharia. Av. Domingos da Costa Lopes, 780 - Jardim Itaipu, Tupã/SP. CEP 17602-496. http://lattes.cnpq.br/2748544348404887. https://orcid. org/0000-0002-4364-2164. ivana.kodama@unesp.br

2 Universidade Estadual Paulista “Júlio de Mesquita Filho" (Unesp). São Paulo/SP, Brasil. http://lattes.cnpq.br/0233732177788776. https://orcid.org/0000-0002-0408-9108. w.lourenzani@unesp.br
} 


\section{INTRODUÇÃO}

O desenvolvimento do biocombustível, que surgiu na interface da agricultura e da energia, tem sido considerado um dos fatores de desenvolvimento agrícola mais significativos dos últimos anos (FAO, 2013). A demanda por alternativas energéticas tem aumentado a produção mundial de biocombustíveis e, consequentemente, o cultivo de culturas alimentares, como a cana-de-açúcar (LOURENZANI; CALDAS, 2014).

$\mathrm{O}$ interesse pelos biocombustíveis foi motivado por diversos fatores, com raízes em profundas repercussões sociais, ambientais e econômicas. Entre eles a diminuição da dependência externa de petróleo e seu impacto na balança de pagamentos, a minimização dos efeitos das emissões veiculares na poluição local e o controle da concentração de gases de efeito estufa (GEE) na atmosfera (SLUZZ; MACHADO, 2006).

Apesar do interesse global pelos biocombustíveis como alternativa para solucionar a crise energética e as mudanças climáticas, torna-se extremamente necessária a avaliação da viabilidade de seu uso, no que diz respeito à produção, comercialização e utilização de forma sustentável (FAO, 2013; DUFT; PICOLI, 2018).

Por isso, diversos debates surgiram, envolvendo problemas de caráter ambiental e social. O levantamento realizado pela divisão de bioenergia e segurança alimentar da FAO (2013) constatou que tais discussões englobam, principalmente, os efeitos na segurança alimentar e no preço das commodities alimentares; na destinação e uso da terra; emissão dos GEE e os efeitos sociais no campo (FAO, 2013; RAVAGNANI, 2014).

Assuntos como a destinação e o uso da terra têm sido fortemente discutidos, posto que as produções da cana-de-açúcar e dos biocombustíveis demandam terra - concorrendo com outras atividades agrícolas - além de contribuírem negativamente com as emissões de GEE, a partir da queima da palha da cana. Nesse sentido, são realizados estudos do balanço energético da cadeia produtiva dos biocombustíveis e a quantidade de gases de efeito estufa emitidos na produção, incluindo as fases agrícola e industrial (LEITE; LEAL, 2007).

Outros problemas, como a perda da biodiversidade, degradação do solo, além de problemas sociais como a exploração da mão de obra e condições precárias de trabalho no campo também são amplamente debatidos na atualidade (CAMARGO et al., 2008; RAVAGNANI, 2014).

O Brasil, contudo, destaca-se com alta potencialidade para a produção de biocombustíveis, especialmente a partir do etanol de cana-de-açúcar, por apresentar balanço energético favorável, consumindo menos energia fóssil para a produção de energia renovável (KOHLHEPP, 2010, SILVA; MIZIARA, 2011).

Principalmente após 2003, com o lançamento do motor flexível ao combustível (FFV flex fuel vehicle) e com interesse por soluções mais limpas para o setor de transportes, ocorreu a expansão da produção do etanol no Brasil e, consequentemente, o aumento da produção da cana-de-açúcar (NASS; PEREIRA; ELLIS, 2007; LEITE; LEAL, 2007).

Além disso, em se tratando do cenário mundial, o país apresenta grande vantagem competitiva devido à sua diversidade edafoclimática, com condições favoráveis para o plantio de culturas destinadas à produção de biocombustíveis (amendoim, babaçu, beterraba, cana-de-açúcar, canola, gergelim, mandioca, mamona, milho, trigo), a disponibilidade de recursos naturais, tecnologia e mão de obra (SLUZZ; MACHADO, 2006). 
Atualmente o Brasil é líder na produção de cana-de-açúcar, representando $39 \%$ da produção e 45\% da exportação mundial (UNICA, 2019; FAO, 2019; IBGE, 2019a). Ocupa a segunda posição na produção de etanol e açúcar, com $28 \%$ da produção mundial (RFA, 2019). No período entre 2003 (surgimento do motor flex fuel) e 2018, tanto a área plantada quanto a produção de cana-de-açúcar no país mais que duplicou (IBGE, 2019a).

Cabe salientar o importante papel da região Centro-Sul na expansão sucroenergética brasileira (Figura 1). Desde 1990, a região é considerada líder no ranking da produção e processamento no setor, com representatividade de mais de $80 \%$ na produção nacional de cana-de-açúcar (CAMARA; CALDARELLI, 2016; UNICA, 2019).

Segundo dados do IBGE (2019a), de toda a expansão nacional ocorrida entre os anos de 2003 e 2018, a concentração foi maior na região Centro-Sul (Figura 1).

Figura 1 - Expansão do cultivo da cana-de-açúcar, por UF nos anos 2003 e 2018

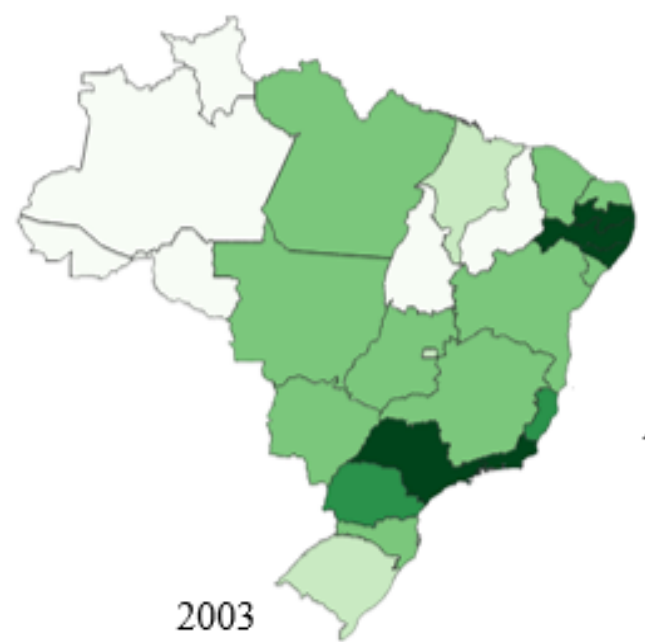

Área cana/ Área total UF (ha)

$0,000000-0,050001$

$0,050001-0,200001$

$0,200001-0,350001$

$0,350001-0,500001$

$0,500001-0,700000$

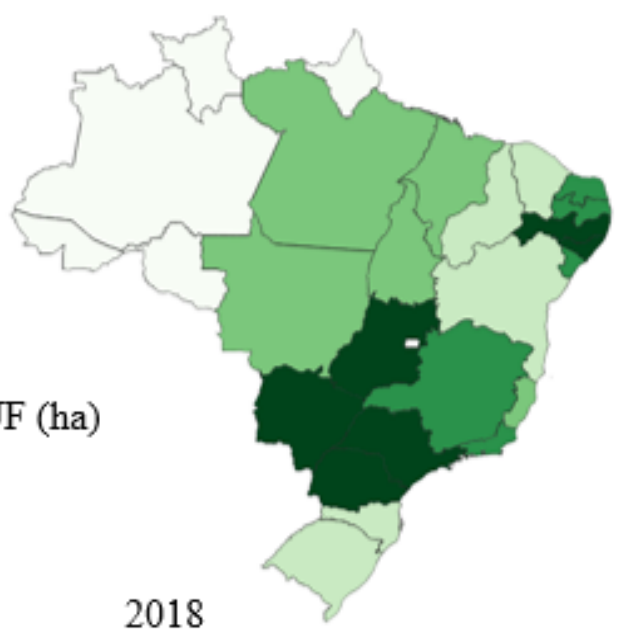

Fonte: Os autores, a partir da base cartográfica do IBGE (2019d) e IPEA (2019).

O Estado de São Paulo é o líder brasileiro do setor sucroenergético (CAMARA; CALDARELLI, 2016). No ano de 2018 o Estado paulista representou 55,2\% da área plantada, 55,32\% da área colhida e 57,99\% da quantidade produzida no país (IBGE, 2019a). Na safra 2018/2019 o Estado representou $62,57 \%$ do açúcar e $48,17 \%$ do etanol produzido no país (UNICA, 2019; USDA, 2019).

A expansão da cana-de-açúcar, porém, não ocorreu de forma homogênea em todo o território do Estado de São Paulo, concentrando-se mais fortemente na região Oeste. Esse processo foi estimulado principalmente por políticas públicas, que atuaram com incentivos para investimentos em infraestrutura, construção e ampliação de usinas, além de aporte à produção e exportação (CAMARGO et al., 2008, RUAS; FERREIRA; BRAY, 2014).

Sendo assim, o objetivo deste artigo é analisar as mudanças no uso da terra na Região Oeste do Estado de São Paulo, no período entre 2003 e 2018, provocadas pela expansão do setor sucroalcooleiro, e, especificamente: (a) caracterizar a dinâmica de expansão da cana-de-açúcar na região em análise e (b) analisar as alterações na composição agropecuária, identificando quais atividades incorporaram e/ou cederam área. 
Compreender as transformações decorrentes da expansão da cana-de-açúcar na região Oeste Paulista pode servir como um importante instrumento de informações para outras regiões do Brasil, cujo potencial para expansão da cana-de-açúcar seja expressivo, contribuindo para a elaboração e instituição de políticas públicas, bem como para a tomada de decisão de agentes públicos e privados.

\section{PROCEDIMENTOS METODOLÓGICOS}

Para a realização deste estudo foram desenvolvidas duas etapas metodológicas. A primeira, de caráter descritivo e qualitativo, constituiu-se de uma pesquisa bibliográfica e documental em fontes de dados secundários (periódicos, livros, dissertações, teses e relatórios), visando a coletar informações e estudos realizados previamente acerca da problemática da expansão do cultivo da cana-de-açúcar.

A segunda etapa constituiu-se de pesquisa de caráter analítico e quantitativo, a fim de analisar as alterações da composição agropecuária na Região Oeste do Estado de São Paulo. Para isso, a fonte de dados consultada foi a Pesquisa Agropecuária Municipal do Sistema IBGE de Recuperação Automática (PAM/Sidra). Os dados geoespaciais, por sua vez, foram obtidos no formato shapefile (".shp") nas bases cartográficas do Instituto Brasileiro de Geografia e Estatística (IBGE) e na malha digital geográfica do Instituto de Pesquisa Econômica Aplicada (IPEAGeo).

Tais dados foram tratados e inseridos em um sistema de informação geográfica (SIG), por meio do software de código aberto "Quantum GIS v. 3.4.13 (QGIS)", visando a construir mapas para a visualização da relação entre a área plantada/área territorial dos municípios pertencentes às mesorregiões do estudo.

O recorte geográfico adotado neste trabalho constitui-se da denominada Região Oeste do Estado de São Paulo, aqui considerada como a integração das Mesorregiões ${ }^{3}$ Araçatuba, Assis, Marília, Presidente Prudente e São José do Rio Preto (Figura 2).

Figura 2 - Recorte geográfico da pesquisa (Região Oeste Paulista)

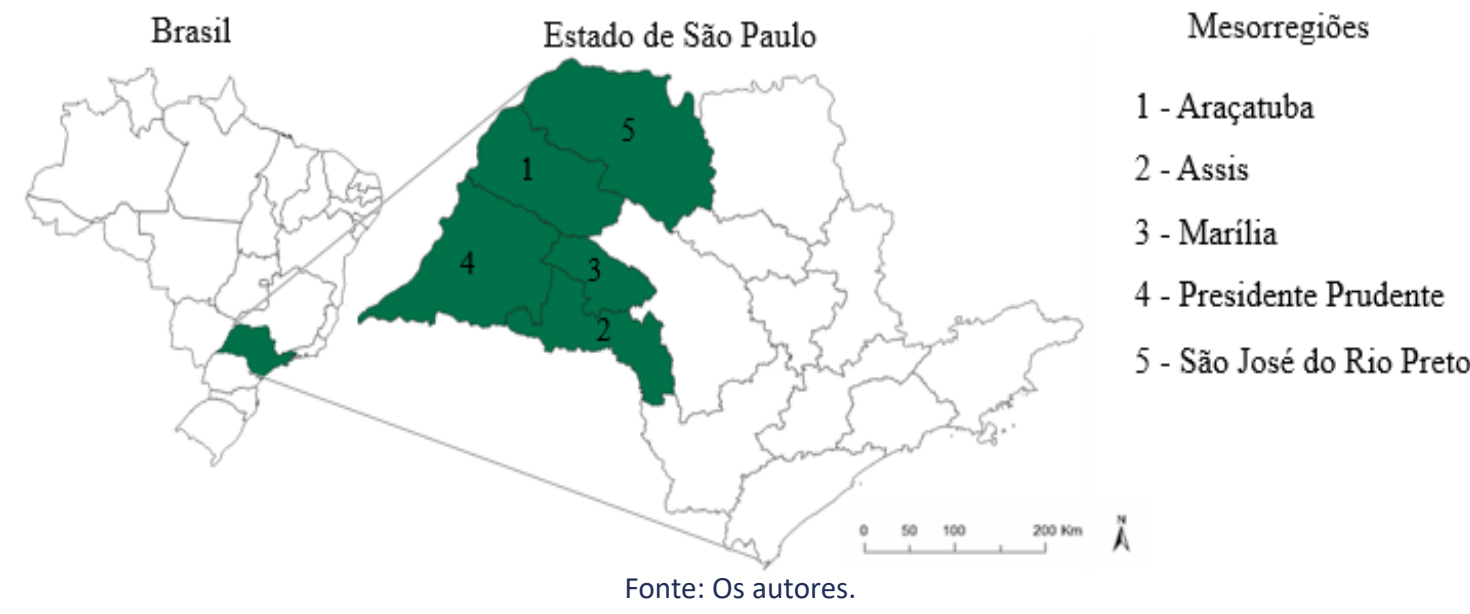

\footnotetext{
${ }^{3}$ Em 1979 o IBGE elaborou o projeto de divisão regional que agrupou municípios com similaridades socioeconômicas em mesorregiões e microrregiões, com o intuito de organizar, planejar e executar funções públicas de interesse comum. Para a formação das mesorregiões foram estabelecidos como critérios: as características sociais, a geografia e a articulação espacial; já para as microrregiões os critérios foram: a estrutura de produção econômica e a articulação espacial (IBGE, 1990).
} 
As unidades de análise, entretanto, serão os municípios constituintes dessas diferentes mesorregiões, representadas a seguir, no Quadro 1.

Quadro 1 - Mesorregiões de estudo e municípios pertencentes

\begin{tabular}{|c|c|}
\hline Mesorregião & Municípios \\
\hline $\begin{array}{c}\text { Araçatuba (34 } \\
\text { municípios) }\end{array}$ & $\begin{array}{l}\text { Alto Alegre, Andradina, Araçatuba, Avanhandava, Barbosa, Bento de Abreu, Bilac, } \\
\text { Birigui, Braúna, Buritama, Castilho, Clementina, Coroados, Gabriel Monteiro, Glicério, } \\
\text { Guaraçaí, Guararapes, Ilha Solteira, Itapura, Lavínia, Lourdes, Luiziânia, Mirandópolis, } \\
\text { Murutinga do Sul, Nova Independência, Penápolis, Pereira Barreto, Piacatu, Rubiacéia, } \\
\text { Santo Antônio do Aracanguá, Santonópolis do Aguapeí, Sud Mennuci, Suzanópolis e } \\
\text { Valparaíso. }\end{array}$ \\
\hline $\begin{array}{c}\text { Assis (34 } \\
\text { municípios) }\end{array}$ & $\begin{array}{l}\text { Assis, Bernardino de Campos, Borá, Campos Novos Paulista, Cândido Mota, Canitar, } \\
\text { Chavantes, Cruzália, Espírito Santo do Turvo, Fartura, Florínea, Ibirarema, lepê, } \\
\text { Ipaussu, Lutécia, Manduri, Maracaí, Nantes, Óleo, Ourinhos, Palmital, Paraguaçu } \\
\text { Paulista, Pedrinhas Paulista, Piraju, Platina, Quatá, Salto Grande, Santa Cruz do Rio } \\
\text { Pardo, São Pedro do Turvo, Sarutaia, Taguaí, Tarumã, Tejupa e Timburi. }\end{array}$ \\
\hline $\begin{array}{l}\text { Marília (20 } \\
\text { municípios) }\end{array}$ & $\begin{array}{l}\text { Álvaro de Carvalho, Alvinlândia, Arco-Íris, Bastos, Echaporã, Fernão, Gália, Garça, } \\
\text { Herculândia, lacri, Lupércio, Marília, Ocauçú, Oriente, Oscar Bressane, Pompéia, } \\
\text { Queiroz, Quintana, Tupã e Vera Cruz. }\end{array}$ \\
\hline $\begin{array}{l}\text { Presidente } \\
\text { Prudente } \\
\text { (53 municípios) }\end{array}$ & $\begin{array}{l}\text { Adamantina, Alfredo Marcondes, Álvares Machado, Anhumas, Caiabú, Caiuá, Dracena, } \\
\text { Emilianópolis, Estrela do Norte, Euclides da Cunha Paulista, Flora Rica, Indiana, } \\
\text { Inúbia Paulista, Irapuru, João Ramalho, Junqueirópolis, Lucélia, Marabá Paulista, } \\
\text { Mariápolis, Martinópolis, Mirante do Paranapanema, Monte Castelo, Narandiba, } \\
\text { Nova Guataporanga, Osvaldo Cruz, Ouro Verde, Pacaembú, Panorama, Parapuã, } \\
\text { Paulicéia, Piqueróbi, Pirapózinho, Pracinha, Presidente Bernardes, Presidente Epitácio, } \\
\text { Presidente Prudente, Presidente Venceslau, Rancharia, Regente Feijó, Ribeirão dos } \\
\text { índios, Rinópolis, Rosana, Sagres, Salmourão, Sandovalina, Santa Mercedes, Santo } \\
\text { Anastácio, Santo Expedito, São João do Pau-D’Alho, Taciba, Tarabaí, Teodoro Sampaio } \\
\text { e Tupi Paulista. }\end{array}$ \\
\hline $\begin{array}{l}\text { São José do Rio } \\
\text { Preto } \\
\text { (107 municípios) }\end{array}$ & $\begin{array}{l}\text { Adolfo, Altair, Alvares Florence, Américo de Campos, Aparecida D’Oeste, Ariranha, } \\
\text { Aspásia, Auriflama, Bady Bassit, Bálsamo, Cajobi, Cardoso, Catanduva, Catiguá, } \\
\text { Cedral, Cosmorama, Dirce Reis, Dolcinópolis, Elisiário, Embaúba, Estrela D’Oeste, } \\
\text { Fernandópolis, Floreal, Gastão Vidigal, General Salgado, Guapiaçu, Guaraci, Guarani } \\
\text { D’Oeste, Guzolândia, Ibirá, Icem, Indiaporã, Ipiguá, Irapuã, Itajobi, Jaci, José Bonifácio, } \\
\text { Macaubal, Macedônia, Magda, Marapoama, Marinópolis, Mendonça, Meridiano, } \\
\text { Mesópolis, Mira Estrela, Mirassol, Mirassolândia, Monções, Monte Aprazível, Neves } \\
\text { Paulista, Nhandeara, Nipoá, Nova Aliança, Nova Canaã Paulista, Nova Castilho, Nova } \\
\text { Granada, Nova Luzitânia, Novais, Novo Horizonte, Olímpia, Onda Verde, Orindiúva, } \\
\text { Ouroeste, Palestina, Palmares Paulista, Palmeira D’Oeste, Paraíso, Paranapuã, Parisi, } \\
\text { Pedranópolis, Pindorama, Planalto, Poloni, Pontalinda, Pontes Gestal, Populina, } \\
\text { Potirendaba, Riolândia, Rubinéia, Sales, Santa Adélia, Santa Albertina, Santa Clara } \\
\text { D’Oeste, Santa Fé do Sul, Santa Rita D'Oeste, Santa Salete, Santana da Ponte Pensa, } \\
\text { São Francisco, São João das Duas Pontes, São João de Iracema, São José do Rio Preto, } \\
\text { Sebastianópolis do Sul, Severínia, Tabapuã, Tanabi, Três Fronteiras, Turmalina, Ubarana, } \\
\text { Uchoa, União Paulista, Urânia, Urupes, Valentim Gentil, Vitória Brasil, Votuporanga e } \\
\text { Zacarias. }\end{array}$ \\
\hline
\end{tabular}

Fonte: Os autores, a partir de Cidade Brasil (2019).

O recorte temporal dos dados utilizados nesta pesquisa foi referente ao período entre 2003 e 2018. O surgimento do carro bicombustível (2003) serviu como ponto de partida de uma nova fase de expansão da cultura de cana-de-açúcar no Brasil. Para identificar a alteração da 
área agricultável na Região Oeste do Estado de São Paulo utilizou-se o modelo Shift-Share (ZOCKUN, 1978; SANTOS; FARIA; TEIXEIRA, 2008; CAMARGO et al., 2008).

Este modelo parte do princípio de que a área agricultável se modifica em um determinado período, devido à alteração do tamanho ou escala do conjunto formado pelas atividades que concorrem pelo fator terra, ou pela substituição de um produto por outro dentro desse conjunto. Por meio da decomposição da variação da área é possível calcular os efeitos Escala (EE) e Substituição (ES) das principais atividades em análise. O modelo analítico utilizado é representado pela expressão:

$A_{i 2}-A_{i 1}=\left(a A_{i 1}-A_{i 1}\right)+\left(A_{i 2}-a A_{i 1}\right)$,

em que:

$A_{i 2}-A_{i 1}=$ variação da área cultivada com uma atividade " $i$ ", entre o período 1 e 2 ;

$\left(\alpha A_{i 1}-A_{i 1}\right)=$ efeito-escala; e $\left(A_{i 2}-\alpha A_{i 1}\right)=$ efeito-substituição,

$a={ }^{\prime} A_{t 2} / A_{t 1} ; A_{t 1}=\sum_{i} A_{i 1} ; A_{t 2}=\sum_{i} A_{i 2}$,

em que:

$A_{t 1}$ e $A_{t 2}$ são as áreas totais ocupadas com as " $n$ " atividades agropecuárias de uma região, respectivamente nos anos 1 e 2 .

O Efeito-Escala (EE) é dado pela variação na área de uma atividade, por meio das alterações de tamanho ou escala dos sistemas, mantendo inalterada sua participação dentro deste. Valores positivos e negativos representam, respectivamente, tendências de expansão ou contração do sistema analisado. De acordo com Santos, Faria e Teixeira (2008), os valores do efeito-escala para cada atividade mostram como seria o seu comportamento se a ampliação ou a contração da área fosse distribuída de forma uniforme entre elas.

O Efeito-Substituição (ES) mostra a variação da participação de uma atividade dentro do sistema, revelando se esta substituiu ou foi substituída por outras atividades. Um valor positivo desse efeito revela que uma atividade substituiu outras, que tiveram um efeito-substituição negativo.

Esse modelo baseia-se na hipótese da proporcionalidade, onde as áreas cedidas por determinadas culturas são proporcionalmente distribuídas para aquelas que expandiram suas áreas. Assim, segundo Camargo et al. (2008), trata-se de um método indicativo e não determinístico, com a capacidade de identificar tendências dos movimentos de substituição.

\section{O SETOR SUCROALCOOLEIRO NO BRASIL}

O cultivo da cana-de-açúcar no Brasil seguiu um caminho que perpassa a história e o desenvolvimento do país, dado que a cultura foi incorporada em território brasileiro na fase de colonização pelos portugueses e, desde então, tem experimentado intenso desenvolvimento agronômico e industrial (GOES; MARRA; SILVA, 2008).

De acordo com Queda (1972) e Chequin e Grandi (2016), é possível observar a relação entre o Estado e as empresas sucroalcooleiras em quatro fases, que acompanham marcos históricos no país. A primeira, decorrente da fundação dos engenhos no Brasil, é caracterizada pela 
concessão das sesmarias aos produtores de açúcar e pela colaboração da Coroa na proteção militar dos engenhos, exigindo que o açúcar nacional produzido fosse comercializado exclusivamente com a metrópole e a um valor abaixo do preço de mercado, inibindo a formação de um mercado interno que rompesse os limites da subsistência (EISENBERG, 1974).

De acordo com o autor, na segunda etapa, a Coroa Portuguesa incentivou a produção de açúcar, impondo quantidades e tributação pelos lucros. Pouco tempo depois, na terceira fase, que ocorreu após a Independência do Brasil, o setor passava por um contexto internacional com incentivos para exportação e a modernização tecnológica nos engenhos centrais e na estação experimental de Campos/RJ, visando a fomentar a produção e comercialização na iniciativa privada (EISENBERG, 1974; QUEDA, 1972).

A indústria açucareira nacional, contudo, foi perdendo espaço para outros países, como os Estados Unidos e países da Europa, em decorrência da expansão mundial de mercados consumidores, os quais começam a produzir açúcar de outras plantas, como a beterraba e o milho. Por fim, na quarta fase, acompanhada pela crise de 1930, ocorreu a intensificação da intervenção estatal no controle e no planejamento da produção açucareira (EISENBERG, 1974; QUEDA, 1972).

Segundo Zanzarini, Santos e Albino (2008), a real expansão do cultivo teve início na década de 70, quando os projetos governamentais passaram a fomentar a produção em decorrência da relevância do produto no desenvolvimento nacional. Com a percepção de que o país poderia se inserir no mercado internacional, o governo interveio na situação agrária e redefiniu a produção, antes voltada majoritariamente para o cultivo de grãos (BARBOSA et al., 2011).

Mediante a forte repercussão da cana-de-açúcar para a produção do etanol, criaram-se diversos programas, com o Programa Nacional do Álcool (ProÁlcool) constituindo o que obteve maior sucesso na época. Instituído em 1975 o programa era subsidiado por financiamentos públicos, oriundos da parceria entre o governo federal e a Petróleo Brasileiro S/A (Petrobras), que se responsabilizava pela mistura, compra, distribuição e precificação do produto (MICHELLON; SANTOS; RODRIGUES, 2008).

Em pouco tempo, no entanto, o Proálcool passou por um período de declínio agravado pelas oscilações nos preços do petróleo e açúcar e pela retirada dos subsídios governamentais decorrentes dos problemas financeiros enfrentados pelo país. $O$ descrédito do Programa intensificou-se ainda mais com a segunda crise do petróleo em 1989 (MICHELLON; SANTOS; RODRIGUES, 2008).

As alterações no panorama de produção podem ser justificadas também por motivos comerciais (BARBOSA et al., 2011). Em meados do século 20 a negociação do açúcar como commodity era arriscada, pois o produto passava por bruscas quedas de preço no mercado externo, e o Brasil, que importava cerca de $80 \%$ de petróleo, viu-se obrigado a diminuir a importação devido ao peso que este representava na balança comercial com o choque do petróleo em 1973 (MICHELLON; SANTOS; RODRIGUES, 2008).

Em relação às questões tecnológicas, entretanto, o país ainda precisava de estímulos. Segundo Eisenberg (1977), o atraso tecnológico nos períodos colonial e imperial ocorreu devido a diversos motivos, entre eles a abundância de terras, a exploração do trabalho escravo e a carência de recursos financeiros de muitos senhores de engenho. Tais fatores foram desestimulando a adoção de novas tecnologias e inovações no setor, reforçando a necessidade da parceria entre as classes proprietárias do ramo junto ao Estado, buscando compensar a defasagem tecnológica diante da concorrência externa (CHEQUIN; GRANDI, 2016). 
Assim, por volta do século 19, a política adotada para fomentar a produção açucareira foi desvalorizar as taxas de câmbio para que o preço do açúcar fosse competitivo no mercado internacional. Esta política, no entanto, elevou os preços dos equipamentos para modernizar a produção do açúcar no Brasil, e a solução foi a concessão de subsídios estatais aos empresários que tinham interesse em modernizar sua produção (CHEQUIN; GRANDI, 2016).

Já no início do século 21 o setor agrícola no Brasil passou por um novo ciclo no cultivo da cana-de-açúcar, que não era mais destinada apenas para a substituição do consumo de petróleo, pela elevação dos preços que ocorreu em 1970 com a criação do ProÁlcool, e sim para atender à crescente demanda por biocombustíveis no país (CAMARGO et al., 2008).

Atualmente o Brasil é líder na produção de cana-de-açúcar, com grande representatividade mundial na produção e exportação tanto do açúcar quanto do etanol. No período entre 2003 e 2018 tanto a área plantada quanto a produção de cana-de-açúcar no país mais que duplicou. Em 2018 a área plantada no Brasil foi de cerca de 10 milhões de hectares, e São Paulo foi o Estado com a maior participação na produção nacional, com $55 \%$ do total, ou 5,5 milhões de hectares de área plantada e produção de 433 milhões de toneladas (IBGE, 2019a).

\section{Impactos e desafios sobre o setor sucroalcooleiro}

A grande demanda por combustíveis provenientes de fontes renováveis cria oportunidades para uma expansão canavieira sem precedentes históricos no Brasil. $O$ país vem se destacando no cenário mundial como uma grande potência na produção de cana-de-açúcar e da industrialização e comercialização de seus subprodutos para o mercado nacional e internacional, devido às mudanças no estilo de desenvolvimento e pela conjuntura econômica na qual se insere (BARBOSA et al., 2011).

As promissoras projeções de demanda por etanol no mercado internacional foram sendo supridas pelo aumento da área plantada com cana-de-açúcar, e que, aliado à introdução de novas tecnologias no setor, aumentaram a produtividade em toda a cadeia deste produto no Brasil (NASS; PEREIRA; ELLIS, 2007; TOLMASQUIM, 2012).

Com a expansão acelerada do setor, têm-se desencadeado inúmeros questionamentos que envolvem desde os impactos socioeconômicos sobre as regiões produtoras até as questões sociais, ambientais, de segurança alimentar, problemas hídricos e questões fundiárias (GILIO, 2015 apud CAMARA; CALDARELLI, 2016).

Impactos positivos são discutidos por Camara e Caldarelli (2016), que ressaltam a possibilidade de crescimento econômico advindo do setor, com geração de emprego e renda e benefícios líquidos positivos à região produtora da cana-de-açúcar. Dada a grande preocupação sobre os efeitos danosos ao meio ambiente, para a atividade sucroalcooleira manter-se competitiva e explorar novos mercados é essencial que o setor adote práticas agrícolas com baixos impactos ambientais (CAMARGO et al., 2008).

Além disso, para assegurar que as decisões de consumo e produção de etanol contribuam para um uso mais eficiente dos recursos naturais, faz-se necessário encontrar formas de fazer incidir os custos socioambientais externos no preço do produto, além de tomar medidas para mitigar os efeitos danosos ao meio ambiente gerados pelas usinas (CAMARGO et al., 2008). 


\section{EXPANSÃO CANAVIEIRA NO BRASIL E OS EFEITOS NO USO DA TERRA NA REGIÃO OESTE PAULISTA}

O Brasil é o maior produtor de cana-de-açúcar no mundo, além de contar com cerca de 410 unidades agroindustriais produtoras de açúcar e álcool, apresentando vantagens competitivas no mercado internacional em relação a outros países produtores (GUIMARÃES, 2016; NOVACANA, 2019).

De acordo com os dados da FAO (2019), em 2017, com 758 milhões de toneladas, o país representava 38,97\% da produção mundial, seguido pela Índia $(15,73 \%)$, China $(10,77 \%)$, Tailândia (5,29\%), Paquistão (3,77\%) e México (2,93\%). Os seis países juntos representam mais de $75 \%$ da produção mundial da cana-de-açúcar. No período de análise (2003-2018) o Brasil teve um aumento na representatividade da produção mundial de 11,92\%, enquanto a Índia e a China reduziram suas participações em 3,91\% e 1,71\%, respectivamente (Gráfico 1).

Gráfico 1 - Participação (\%) dos maiores produtores mundiais de cana-de-açúcar (2003-2017)

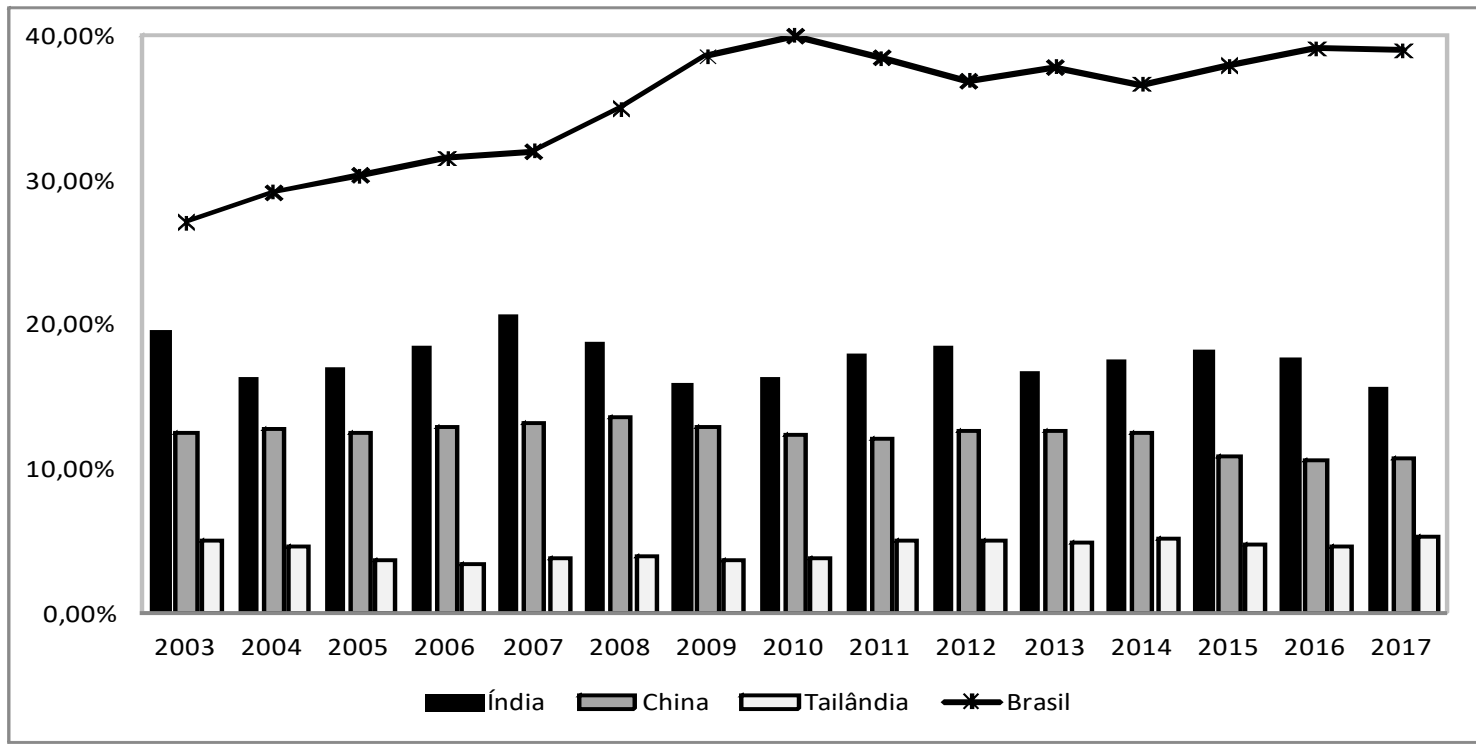

Fonte: Os autores, a partir de dados da FAO (2019).

Entre 2003 e 2018 a área plantada com cana-de-açúcar duplicou no Brasil, passando de cerca de 5 milhões de hectares para mais de 10 milhões. Nesse período o Estado de São Paulo teve grande destaque na expansão do setor canavieiro brasileiro, assumindo $58 \%$ desse processo (IBGE, 2019a). Em 2003 o Estado paulista representava 52,4\% da área plantada no Brasil e, em 2018, passou para 55,2\% (Gráfico 2).

Apesar de sua expressividade em âmbito nacional, a expansão da cana-de-açúcar não ocorreu de forma homogênea no Estado. O mapa apresentado pela Figura 3 revela o grau de ocupação dessa cultura entre 2003 e 2018. A relação entre a área plantada de cana-de-açúcar e a área do município, no período analisado, revela o forte processo de expansão para a região Oeste do Estado. 


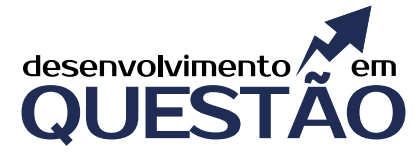

MUDANÇAS NO USO DA TERRA A PARTIR DA EXPANSÃO DO CULTIVO DA CANA-DE-AÇÚCAR NA REGIÃO OESTE DO ESTADO DE SÃO PAULO

Ivana Sayuri Kodama - Wagner Luiz Lourenzani

Gráfico 2 - Representatividade (\%) do Estado de São Paulo na produção nacional de cana-de-açúcar (2003-2018)

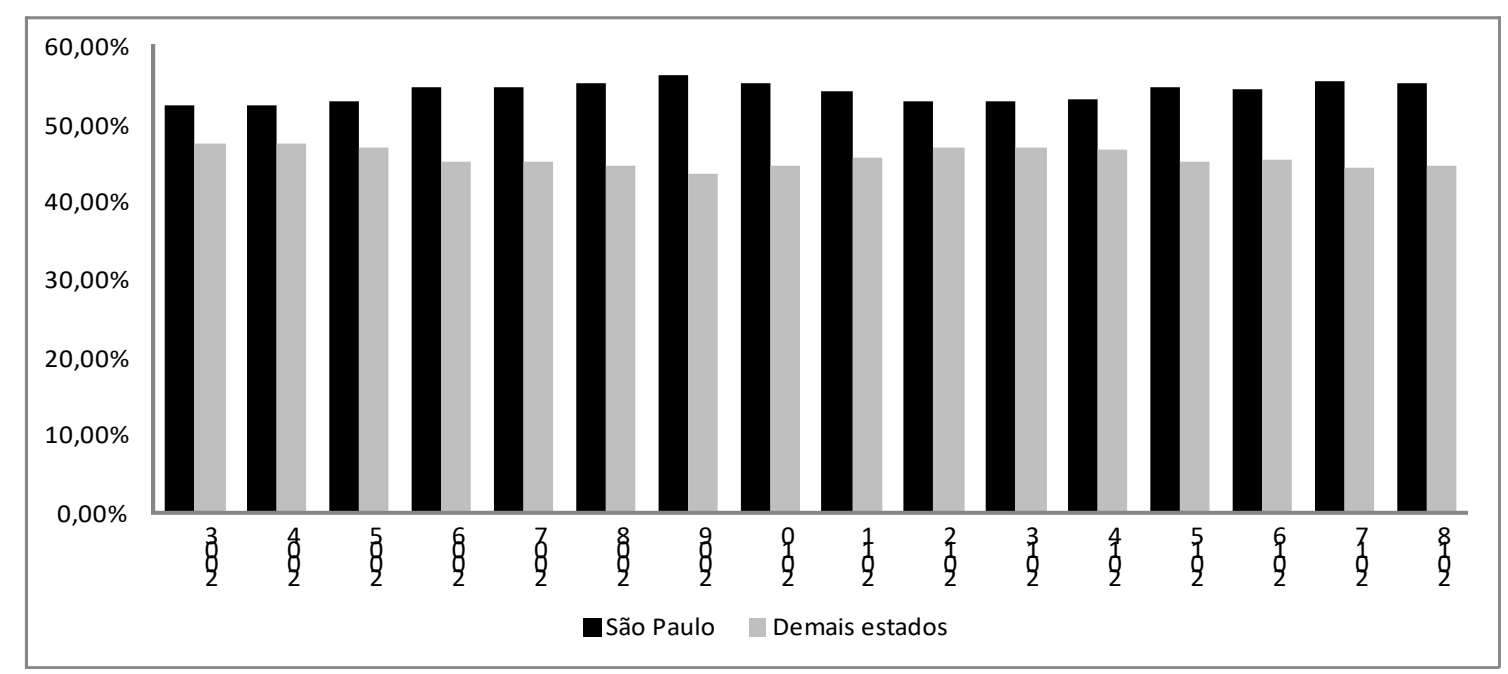

Fonte: Os autores, a partir de dados do IBGE (2019a).

Figura 3 - Expansão do cultivo de cana-de-açúcar, no Estado de São Paulo, entre 2003 e 2018

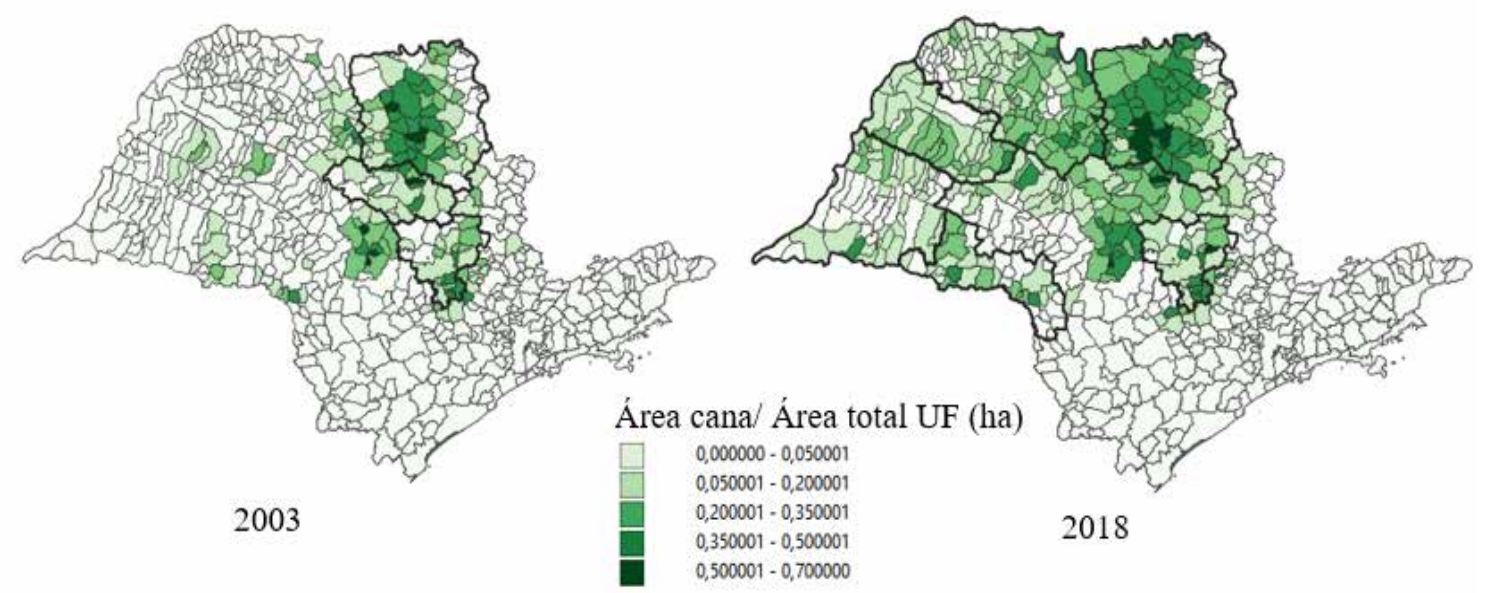

Fonte: Os autores, a partir da base cartográfica do IBGE (2019a, d) e IPEA (2019).

A partir de 2003 as áreas de produção expandiram-se a partir das mesorregiões Centro-Norte do Estado (Araraquara, Campinas, Piracicaba, Ribeirão Preto) para a Região Oeste em 2018 (Araçatuba, Assis, Marília, Presidente Prudente e São José do Rio Preto), demonstrando forte representatividade da região nessa dinâmica agrícola (Figura 4).

De acordo com o Gráfico 3, percebe-se que a área plantada com cana-de-açúcar na Região Oeste Paulista triplicou entre 2003 e 2018, passando de 800 mil para mais de 2,5 milhões de hectares. Destaque para a mesorregião de São José do Rio Preto, que passou de $5 \%$ para $10 \%$ na representatividade de área cultivada com cana-de-açúcar em todo o Estado de São Paulo. 
MUDANÇAS NO USO DA TERRA A PARTIR DA EXPANSÃO DO CULTIVO DA CANA-DE-AÇÚCAR NA REGIÃO OESTE DO ESTADO DE SÃO PAULO

Ivana Sayuri Kodama - Wagner Luiz Lourenzani

Figura 4 - Participação da área de cana-de-açúcar em relação à área do município, na região Oeste Paulista, nos anos de 2003 e 2018
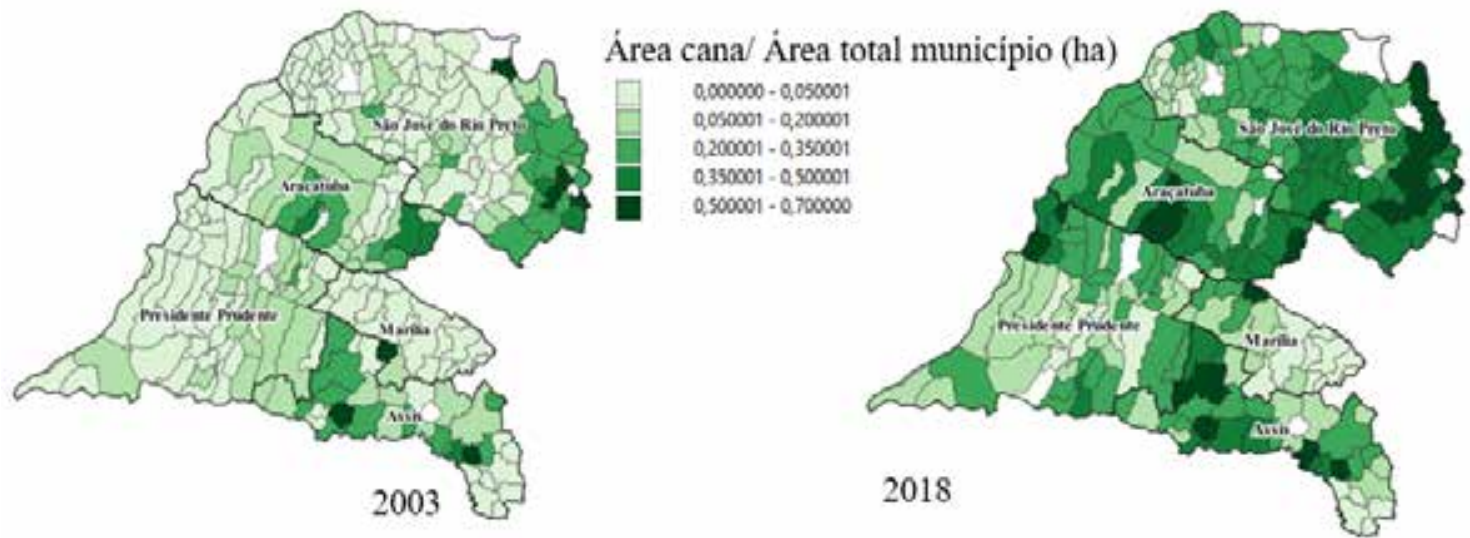

Fonte: Os autores, a partir da base cartográfica do IBGE (2019a, d) e IPEA (2019).

Gráfico 3 - Área de cana-de-açúcar (ha) - Mesorregiões do Oeste Paulista, 2003 e 2018

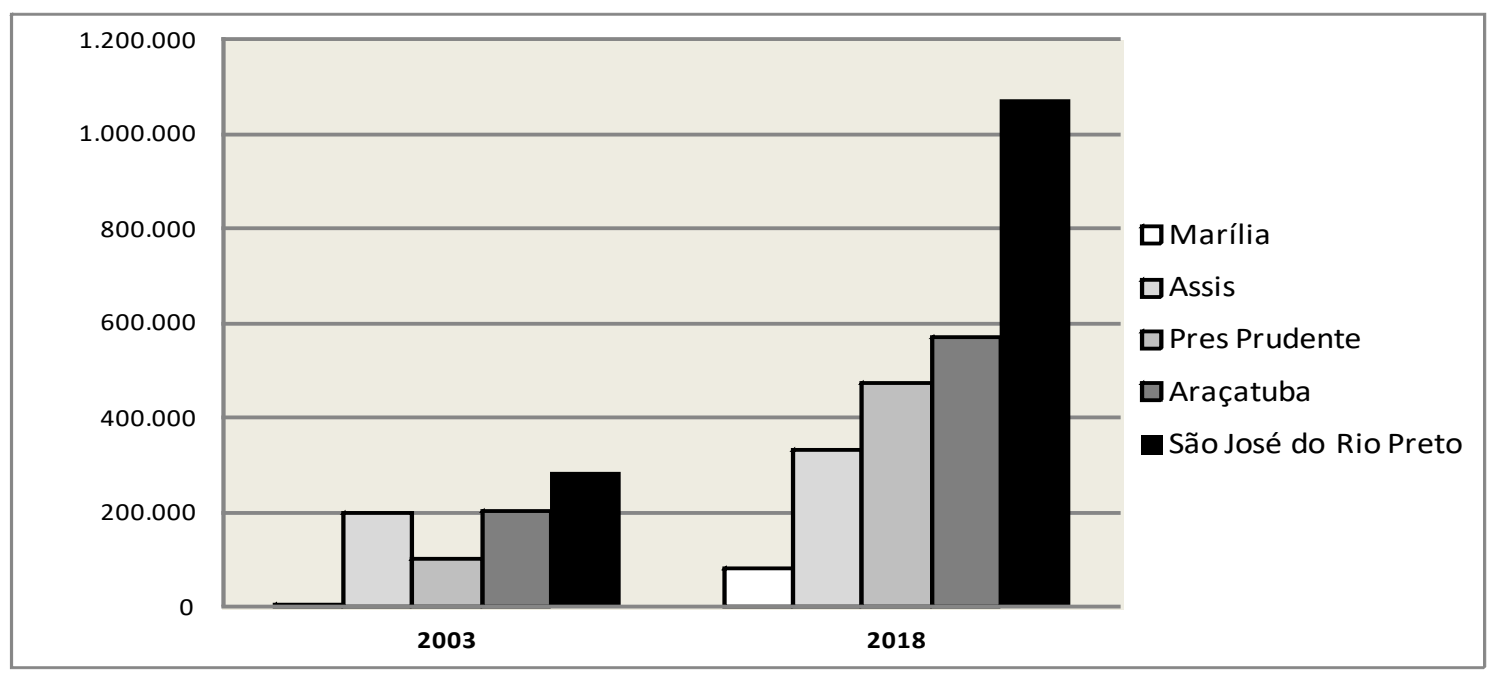

Fonte: Os autores, a partir de dados do IBGE (2019a).

\section{Mudanças do uso da terra nas Mesorregiões do Oeste Paulista}

Os tópicos a seguir apresentam os resultados das análises sobre os efeitos Escala e Substituição, permitindo a visualização das modificações ocorridas na composição agropecuária nas Mesorregiões em análise deste estudo.

\section{Mesorregião Araçatuba}

Observando-se a mudança do uso da terra na mesorregião de Araçatuba (Tabela 1), entre 2003 e 2018, é possível identificar que houve um aumento da área cultivável de aproximadamente 303 mil hectares, ou seja, acréscimo de $80 \%$ da área de produção agrícola da mesorregião. Considera-se que parte significativa desse incremento deu-se por meio da subs- 
tituição de áreas de pastagens ${ }^{4}$ (atividade pecuária). No período analisado, o rebanho bovino passou de 1,6 milhão de cabeças para 1 milhão, com decréscimo de cerca de 40\% (IBGE, 2019c).

Tabela 1 - Efeitos Escala (EE) e Substituição (ES) da Mesorregião Araçatuba, entre 2003 e 2018

\begin{tabular}{|c|c|c|c|c|c|c|}
\hline \multirow{2}{*}{$\begin{array}{c}\text { Mesorregião } \\
\text { Araçatuba }\end{array}$} & \multicolumn{2}{|c|}{---Área cultivada (ha)--- } & \multicolumn{2}{|c|}{---Variação da Área--- } & \multirow{2}{*}{$\begin{array}{r}E E \\
\text { (ha) } \\
\end{array}$} & \multirow{2}{*}{$\begin{array}{r}\text { ES } \\
\text { (ha) } \\
\end{array}$} \\
\hline & 2003 & 2018 & (ha) & $(\%)$ & & \\
\hline Cana-de-açúcar & 203.517 & 569.328 & 365.811 & $180 \%$ & 162.486 & 203.325 \\
\hline Soja & 31.059 & 44.077 & 13.018 & $42 \%$ & 24.797 & -11.779 \\
\hline Borracha & 3.573 & 6.953 & 3.380 & $95 \%$ & 2.853 & 527 \\
\hline Batata-doce & 1 & 2.539 & 2.538 & $253800 \%$ & 1 & 2.537 \\
\hline Amendoim & 450 & 2.893 & 2.443 & $543 \%$ & 359 & 2.084 \\
\hline Laranja & 2.801 & 4.203 & 1.402 & $50 \%$ & 2.236 & -834 \\
\hline Urucum & 3 & 1.066 & 1.063 & $35433 \%$ & 2 & 1.061 \\
\hline Mandioca & 865 & 949 & 84 & $10 \%$ & 691 & -607 \\
\hline Sorgo (em grão) & 6.324 & 5.837 & -487 & $-8 \%$ & 5.049 & -5.536 \\
\hline Outras Permanentes & 1.907 & 867 & -1.040 & $-55 \%$ & 1.523 & -2.563 \\
\hline Tomate & 2.160 & 316 & -1.844 & $-85 \%$ & 1.725 & -3.569 \\
\hline Café & 3.506 & 798 & -2.708 & $-77 \%$ & 2.799 & -5.507 \\
\hline Outras Temporárias & 3.184 & 63 & -3.121 & $-98 \%$ & 2.542 & -5.663 \\
\hline Frutas & 7.871 & 4.605 & -3.266 & $-41 \%$ & 6.284 & -9.550 \\
\hline Feijão & 27.033 & 1.956 & -25.077 & $-93 \%$ & 21.583 & -46.660 \\
\hline Milho & 85.802 & 37.039 & -48.763 & $-57 \%$ & 68.503 & -117.266 \\
\hline TOTAL & 380.056 & 683.489 & 303.433 & $80 \%$ & 303.433 & 0 \\
\hline
\end{tabular}

Fonte: Os autores, a partir de dados do IBGE $(2019 \mathrm{a}, \mathrm{b})$.

Destaca-se o incremento significativo da cultura da cana-de-açúcar no período, passando de 203 mil para 569 mil hectares. Desse incremento, 162 mil ha se devem a incorporação de novas áreas (Efeito Escala) e 203 mil ha ocorrem pela substituição de áreas onde antes havia outras culturas (Efeito Substituição). Além da cana, outras culturas que tiveram aumento de áreas foram a soja, a borracha (seringueira), a batata-doce, o amendoim, a laranja e o urucum. Entre as culturas que mais perderam área estão: milho, feijão, café e frutas (manga, banana e abacaxi).

No que se refere ao Efeito Substituição (Tabela 2), constatou-se que a cana-de-açúcar foi responsável por $97 \%$ da incorporação das áreas de outras culturas, destacando-se que as culturas que mais cederam áreas foram: milho, feijão, soja e frutas.

\footnotetext{
${ }^{4}$ Embora o sistema Sidra/IBGE não apresente dados de áreas de pastagem, por município, considerou-se a redução do rebanho bovino como um indicativo de redução de áreas de pastagens. A taxa de lotação média no Brasil é de cerca de 1,1 cabeça/hectare.
} 
MUDANÇAS NO USO DA TERRA A PARTIR DA EXPANSÃO DO CULTIVO DA CANA-DE-AÇÚCAR NA REGIÃO OESTE DO ESTADO DE SÃO PAULO

Ivana Sayuri Kodama - Wagner Luiz Lourenzani

Tabela 2 - Efeito-substituição (ES) atribuído aos produtos que cederam área, em hectares, na Mesorregião Araçatuba, entre 2003 e 2018

\begin{tabular}{lrrrrrr}
\hline \multicolumn{1}{c}{$\begin{array}{c}\text { Produtos que } \\
\text { cederam área (ha) }\end{array}$} & $\begin{array}{c}\text { - } \\
\text { Cana-de- } \\
\text { açúcar }\end{array}$ & Batata-doce & Amendoim & Urucum & Borracha & Total (ha) \\
\hline Mandioca & 589 & 7 & 6 & 3 & 2 & 607 \\
Laranja & 810 & 10 & 8 & 4 & 2 & 834 \\
Outras Permanentes & 2.487 & 31 & 25 & 13 & 6 & 2.563 \\
Tomate & 3.463 & 43 & 35 & 18 & 9 & 3.569 \\
Café & 5.344 & 67 & 55 & 28 & 14 & 5.507 \\
Sorgo & 5.372 & 67 & 55 & 28 & 14 & 5.536 \\
Outras Temporárias & 5.495 & 69 & 56 & 29 & 14 & 5.663 \\
Frutas & 9.267 & 116 & 95 & 48 & 24 & 9.550 \\
Soja & 11.430 & 143 & 117 & 60 & 30 & 11.779 \\
Feijão & 45.277 & 565 & 464 & 236 & 117 & 46.660 \\
Milho & 113.792 & 1.420 & 1.166 & 594 & 295 & 117.266 \\
\hline TOTAL (ha) & 203.325 & 2.537 & 2.084 & 1.061 & 527 & 209.534 \\
\hline
\end{tabular}

Fonte: Os autores, a partir de dados do IBGE (2019a, b).

\section{Mesorregião Assis}

Na mesorregião de Assis (Tabela 3) é possível identificar que houve um aumento da área cultivável de aproximadamente 230 mil hectares, ou seja, acréscimo de $34 \%$ da área de produção agrícola da mesorregião. Nessa região, considera-se também que parte significativa do incremento da área agrícola ocorreu por meio da substituição de áreas de pastagens (atividade pecuária). No período analisado o rebanho bovino passou de 704 mil cabeças para 489 mil cabeças, com decréscimo de cerca de 31\% (IBGE, 2019c).

Tabela 3 - Efeitos Escala (EE) e Substituição (ES) da Mesorregião Assis, entre 2003 e 2018

\begin{tabular}{|c|c|c|c|c|c|c|}
\hline \multirow{2}{*}{$\begin{array}{c}\text { Mesorregião } \\
\text { Assis }\end{array}$} & \multicolumn{2}{|c|}{---Área cultivada (ha) --- } & \multicolumn{2}{|c|}{---Variação da Área--- } & \multicolumn{2}{|c|}{$\mathrm{EE}$} \\
\hline & 2003 & 2018 & (ha) & $(\%)$ & (ha) & (ha) \\
\hline Cana-de-açúcar & 199.710 & 331.516 & 131.806 & $66 \%$ & 67.737 & 64.069 \\
\hline Soja & 185.160 & 265.389 & 80.229 & $43 \%$ & 62.802 & 17.427 \\
\hline Milho & 209.054 & 242.571 & 33.517 & $16 \%$ & 70.907 & -37.390 \\
\hline Frutas & 4.647 & 17.887 & 13.240 & $285 \%$ & 1.576 & 11.664 \\
\hline Amendoim & 3.480 & 10.092 & 6.612 & $190 \%$ & 1.180 & 5.432 \\
\hline Cereais & 2 & 3.355 & 3.353 & $167650 \%$ & 1 & 3.352 \\
\hline Tangerina & 908 & 1.007 & 99 & $11 \%$ & 308 & -209 \\
\hline Borracha & 47 & 101 & 54 & $115 \%$ & 16 & 38 \\
\hline Outras Permanentes & 185 & 175 & -10 & $-5 \%$ & 63 & -73 \\
\hline Limão & 330 & 148 & -182 & $-55 \%$ & 112 & -294 \\
\hline Outras Temporárias & 2.446 & 1.234 & -1.212 & $-50 \%$ & 830 & -2.042 \\
\hline Banana & 2.169 & 499 & -1.670 & $-77 \%$ & 736 & -2.406 \\
\hline Arroz & 2.661 & 615 & -2.046 & $-77 \%$ & 903 & -2.949 \\
\hline Feijão & 10.264 & 8.034 & -2.230 & $-22 \%$ & 3.481 & -5.711 \\
\hline Mandioca & 13.412 & 8.041 & -5.371 & $-40 \%$ & 4.549 & -9.920 \\
\hline Café & 23.828 & 18.357 & -5.471 & $-23 \%$ & 8.082 & -13.553 \\
\hline Trigo & 22.650 & 2.897 & -19.753 & $-87 \%$ & 7.682 & -27.435 \\
\hline TOTAL & 680.953 & 911.918 & 230.965 & $34 \%$ & 230.965 & 0 \\
\hline
\end{tabular}


No período analisado houve um incremento significativo da cultura da cana-de-açúcar, passando de 199 mil para 331 mil hectares. Desse incremento, 67 mil ha devem-se à incorporação de novas áreas (Efeito Escala) e 64 mil ha pela substituição de áreas onde antes havia outras culturas (Efeito Substituição).

Além da cana, outras culturas que tiveram aumento de áreas foram a soja, milho, frutas, amendoim e cereais. Entre as culturas que mais perderam área estão: trigo, café, mandioca, feijão e arroz.

No que se refere ao Efeito Substituição (Tabela 4), constatou-se que a cana-de-açúcar foi responsável por $63 \%$ da incorporação das áreas de outras culturas, destacando-se que as culturas que mais cederam áreas foram: milho, trigo, café, feijão, arroz e mandioca, esses últimos produtos característicos da pequena produção e da cesta básica.

Tabela 4 - Efeito-substituição (ES) atribuído aos produtos que cederam área, em hectares, na Mesorregião Assis, entre 2003 e 2018

\begin{tabular}{|c|c|c|c|c|c|c|c|}
\hline \multirow{2}{*}{$\begin{array}{c}\text { Produtos que } \\
\text { cederam área (ha) }\end{array}$} & \multicolumn{7}{|c|}{----------------------- Produtos que incorporaram área (ha) -------------------------- } \\
\hline & Cana-de-açúcar & Soja & Frutas & Amendoim & Cereais & Borracha & Total (ha) \\
\hline Outras Permanentes & 46 & 12 & 8 & 4 & 2 & 0 & 73 \\
\hline Tangerina & 131 & 36 & 24 & 11 & 7 & 0 & 209 \\
\hline Limão & 185 & 50 & 34 & 16 & 10 & 0 & 294 \\
\hline Outras Temporárias & 1.283 & 349 & 234 & 109 & 67 & 1 & 2.042 \\
\hline Banana & 1.511 & 411 & 275 & 128 & 79 & 1 & 2.406 \\
\hline Arroz & 1.852 & 504 & 337 & 157 & 97 & 1 & 2.949 \\
\hline Feijão & 3.588 & 976 & 653 & 304 & 188 & 2 & 5.711 \\
\hline Mandioca & 6.232 & 1.695 & 1.135 & 528 & 326 & 4 & 9.920 \\
\hline Café & 8.515 & 2.316 & 1.550 & 722 & 446 & 5 & 13.553 \\
\hline Trigo & 17.236 & 4.688 & 3.138 & 1.461 & 902 & 10 & 27.435 \\
\hline Milho & 23.490 & 6.389 & 4.276 & 1.991 & 1.229 & 14 & 37.390 \\
\hline TOTAL (ha) & 64.069 & & & 5.432 & 3.352 & 38 & 101.982 \\
\hline
\end{tabular}

Fonte: Os autores, a partir de dados do IBGE (2019a, b).

\section{Mesorregião Marília}

Na mesorregião de Marília (Tabela 5) também houve um aumento da área cultivável de aproximadamente 89 mil hectares, ou seja, acréscimo de 107\% da área de produção agrícola da mesorregião. Da mesma forma que as outras regiões, considera-se que parte significativa desse incremento ocorreu por meio da substituição de áreas de pastagens (atividade pecuária). No período analisado o rebanho bovino passou de 804 mil cabeças para 620 mil, com decréscimo de cerca de $23 \%$ (IBGE, 2019c).

Tabela 5 - Efeitos Escala (EE) e Substituição (ES) da Mesorregião Marília, entre 2003 e 2018

\begin{tabular}{|c|c|c|c|c|c|c|}
\hline \multirow{2}{*}{$\begin{array}{c}\text { Mesorregião } \\
\text { Marília }\end{array}$} & \multicolumn{2}{|c|}{---Área cultivada (ha) --- } & \multicolumn{2}{|c|}{---Variação da Área--- } & \multirow{2}{*}{$\begin{array}{l}\text { EE } \\
\text { (ha) }\end{array}$} & \multirow{2}{*}{$\begin{array}{c}\text { ES } \\
\text { (ha) }\end{array}$} \\
\hline & 2003 & 2018 & (ha) & $(\%)$ & & \\
\hline Cana-de-açúcar & 6.363 & 84.009 & 77.646 & $1220 \%$ & 6.785 & 70.861 \\
\hline Mandioca & 3.307 & 9.703 & 6.396 & $193 \%$ & 3.527 & 2.869 \\
\hline Soja & 2.213 & 8.257 & 6.044 & $273 \%$ & 2.360 & 3.684 \\
\hline Amendoim & 17.548 & 22.865 & 5.317 & $30 \%$ & 18.713 & -13.396 \\
\hline
\end{tabular}




\begin{tabular}{|c|c|c|c|c|c|c|}
\hline Laranja & 429 & 2.875 & 2.446 & $570 \%$ & 457 & 1.989 \\
\hline Borracha & 2.186 & 2.797 & 611 & $28 \%$ & 2.331 & -1.720 \\
\hline Frutas & 3.306 & 2.554 & -752 & $-23 \%$ & 3.525 & -4.277 \\
\hline $\begin{array}{l}\text { Outras } \\
\text { Temporárias }\end{array}$ & 746 & 517 & -229 & $-31 \%$ & 796 & -1.025 \\
\hline $\begin{array}{l}\text { Outras } \\
\text { Permanentes }\end{array}$ & 1.523 & 608 & -915 & $-60 \%$ & 1.624 & -2.539 \\
\hline Café & 26.644 & 25.037 & -1.607 & $-6 \%$ & 28.413 & -30.020 \\
\hline Feijão & 2.054 & 363 & -1.691 & $-82 \%$ & 2.190 & -3.881 \\
\hline Milho & 17.847 & 14.335 & -3.512 & $-20 \%$ & 19.032 & -22.544 \\
\hline TOTAL & 84.166 & 173.920 & 89.754 & $107 \%$ & 89.754 & 0 \\
\hline
\end{tabular}

Fonte: Os autores, a partir de dados do IBGE (2019a, b).

Destaca-se o incremento significativo da cultura da cana-de-açúcar no período, passando de 6 mil para 84 mil hectares. Desse incremento, 6 mil ha devem-se à incorporação de novas áreas (Efeito Escala) e 70 mil ha pela substituição de áreas onde antes havia outras culturas (Efeito Substituição).

Além da cana, outras culturas que tiveram aumento de áreas foram a mandioca, soja, amendoim e laranja. Entre as culturas que mais perderam área estão: milho, feijão, café e outras culturas permanentes.

No que se refere ao Efeito Substituição (Tabela 6), constatou-se que a cana-de-açúcar foi responsável por $89 \%$ da incorporação das áreas de outras culturas, seguida pela soja (5\%), mandioca (4\%) e laranja (3\%), observando-se que as culturas que mais cederam áreas foram: café, milho, amendoim e frutas.

Tabela 6 - Efeito-substituição (ES) atribuído aos produtos que cederam área, em hectares, na Mesorregião Marília, entre 2003 e 2018

\begin{tabular}{lrrrrr}
\hline \begin{tabular}{l} 
Produtos que cederam \\
\multicolumn{1}{c}{ área (ha) }
\end{tabular} & Cana-de-açúcar & \multicolumn{1}{c}{ Soja } & Mandioca & Laranja & Total (ha) \\
\hline Outras Temporárias & 914 & 48 & 37 & 26 & 1.025 \\
Borracha & 1.535 & 80 & 62 & 43 & 1.720 \\
Outras Permanentes & 2.266 & 118 & 92 & 64 & 2.539 \\
Feijão & 3.464 & 180 & 140 & 97 & 3.881 \\
Frutas & 3.817 & 198 & 155 & 107 & 4.277 \\
Amendoim & 11.955 & 622 & 484 & 335 & 13.396 \\
Milho & 20.119 & 1.046 & 815 & 565 & 22.544 \\
Café & 26.790 & 1.393 & 1.085 & 752 & 30.020 \\
\hline TOTAL (ha) & 70.861 & 3.684 & 2.869 & 1.989 & 79.403 \\
\hline
\end{tabular}

Fonte: Os autores, a partir de dados do IBGE (2019a, b).

\section{Mesorregião Presidente Prudente}

Observando-se a mudança do uso da terra na mesorregião de Presidente Prudente (Tabela 7), identificou-se que a área cultivável mais que dobrou, partindo de 292 mil hectares em 2003 para 621 mil hectares em 2018, ou seja, acréscimo de 113\% da área de produção agrícola da mesorregião. 
Tabela 7 - Efeitos Escala (EE) e Substituição (ES) da Mesorregião Presidente Prudente, entre 2003 e 2018

\begin{tabular}{|c|c|c|c|c|c|c|}
\hline \multirow{2}{*}{$\begin{array}{l}\text { Mesorregião Presidente } \\
\text { Prudente }\end{array}$} & \multicolumn{2}{|c|}{---Área cultivada (ha) --- } & \multicolumn{2}{|c|}{---Variação da Área--- } & \multirow{2}{*}{$\mathrm{EE}$} & \multirow{2}{*}{ (ha) } \\
\hline & 2003 & 2018 & (ha) & $(\%)$ & & \\
\hline Cana-de-açúcar & 102.858 & 472.651 & 369.793 & $360 \%$ & 115.785 & 254.008 \\
\hline Amendoim & 7.810 & 20.364 & 12.554 & $161 \%$ & 8.792 & 3.762 \\
\hline Mandioca & 3.195 & 10.453 & 7.258 & $227 \%$ & 3.597 & 3.661 \\
\hline Urucum & 1.474 & 4.227 & 2.753 & $187 \%$ & 1.659 & 1.094 \\
\hline Borracha & 3.231 & 4.704 & 1.473 & $46 \%$ & 3.637 & -2.164 \\
\hline Batata-doce & 2.424 & 3.366 & 942 & $39 \%$ & 2.729 & -1.787 \\
\hline Sorgo & 716 & 1.365 & 649 & $91 \%$ & 806 & -157 \\
\hline Outras permanentes & 365 & 142 & -223 & $-61 \%$ & 411 & -634 \\
\hline Frutas & 5.448 & 3.886 & -1.562 & $-29 \%$ & 6.133 & -7.695 \\
\hline Outras temporárias & 3.966 & 381 & -3.585 & $-90 \%$ & 4.464 & -8.049 \\
\hline Soja & 53.720 & 47.084 & -6.636 & $-12 \%$ & 60.471 & -67.107 \\
\hline Algodão & 7.737 & 862 & -6.875 & $-89 \%$ & 8.709 & -15.584 \\
\hline Café & 16.588 & 6.567 & -10.021 & $-60 \%$ & 18.673 & -28.694 \\
\hline Feijão & 16.040 & 1.387 & -14.653 & $-91 \%$ & 18.056 & -32.709 \\
\hline Milho & 66.803 & 44.055 & -22.748 & $-34 \%$ & 75.198 & -97.946 \\
\hline TOTAL & 292.375 & 621.494 & 329.119 & $113 \%$ & 329.119 & 0 \\
\hline
\end{tabular}

Fonte: Os autores, a partir de dados do IBGE (2019a, b).

Considera-se que parte significativa desse incremento deu-se por meio da substituição de áreas de pastagens (atividade pecuária). No período analisado o rebanho bovino passou de 2,7 milhões de cabeças para 2 milhões, com decréscimo de cerca de 40\% (IBGE, 2019c).

Destaca-se o incremento significativo da cultura da cana-de-açúcar no período, passando de 102 mil para 472 mil hectares. Desse incremento, 115 mil ha devem-se à incorporação de novas áreas (Efeito Escala) e 254 mil ha pela substituição de áreas nas quais antes havia outras culturas (Efeito Substituição).

Além da cana, outras culturas que tiveram aumento de áreas foram o amendoim, mandioca, urucum e borracha (seringueira). Entre as culturas que mais perderam área estão: milho, feijão, café, algodão e soja.

No que se refere ao Efeito Substituição (Tabela 8), constatou-se que a cana-de-açúcar foi responsável por $97 \%$ da incorporação das áreas de outras culturas, destacando-se que as culturas que mais cederam áreas foram: milho, soja, feijão, café e algodão.

Tabela 8 - Efeito-substituição (ES) atribuído aos produtos que cederam área, em hectares, na Mesorregião Presidente Prudente, entre 2003 e 2018

\begin{tabular}{|c|c|c|c|c|c|}
\hline \multirow{2}{*}{$\begin{array}{c}\text { Produtos que } \\
\text { cederam área (ha) }\end{array}$} & \multicolumn{5}{|c|}{---------------------- Produtos que incorporaram área (ha) ------------------------- } \\
\hline & Cana-de-açúcar & Amendoim & Mandioca & Urucum & Total (ha) \\
\hline Sorgo & 152 & 2 & 2 & 1 & 157 \\
\hline Outras permanentes & 613 & 9 & 9 & 3 & 634 \\
\hline Batata-doce & 1.729 & 26 & 25 & 7 & 1.787 \\
\hline Borracha & 2.094 & 31 & 30 & 9 & 2.164 \\
\hline Frutas & 7.445 & 110 & 107 & 32 & 7.695 \\
\hline Outras temporárias & 7.788 & 115 & 112 & 34 & 8.049 \\
\hline Algodão & 15.079 & 223 & 217 & 65 & 15.584 \\
\hline
\end{tabular}




\begin{tabular}{lrrrrr} 
& & & & & \\
Café & 27.763 & 411 & 400 & 120 & 28.694 \\
Feijão & 31.648 & 469 & 456 & 136 & 32.709 \\
Soja & 64.930 & 962 & 936 & 280 & 67.107 \\
Milho & 94.769 & 1.404 & 1.366 & 408 & 97.946 \\
\hline TOTAL (ha) & 254.008 & 3.762 & 3.661 & 1.094 & 262.526 \\
\hline
\end{tabular}

Fonte: Os autores, a partir de dados do IBGE (2019a, b).

\section{Mesorregião São José do Rio Preto}

Ao analisar a mesorregião de São José do Rio Preto (Tabela 9), verifica-se um aumento da área cultivável de aproximadamente 684 mil hectares, ou seja, um acréscimo de 132\% da área de produção agrícola da mesorregião.

Tabela 9 - Efeitos Escala (EE) e Substituição (ES) da Mesorregião São José do Rio Preto, entre 2003 e 2018

\begin{tabular}{|c|c|c|c|c|c|c|}
\hline \multirow{2}{*}{$\begin{array}{l}\text { Mesorregião São José do } \\
\text { Rio Preto }\end{array}$} & \multicolumn{2}{|c|}{---Área cultivada (ha) --- } & \multicolumn{2}{|c|}{---Variação da Área--- } & \multirow{2}{*}{$\begin{array}{l}\text { EE } \\
\text { (ha) }\end{array}$} & \multirow{2}{*}{$\begin{array}{l}\text { ES } \\
\text { (ha) }\end{array}$} \\
\hline & 2003 & 2018 & (ha) & (\%) & & \\
\hline Cana-de-açúcar & 287.998 & 1.075 .623 & 787.625 & $273 \%$ & 380.530 & 407.095 \\
\hline Amendoim & 5.636 & 19.903 & 14.267 & $253 \%$ & 7.447 & 6.820 \\
\hline Soja & 24.130 & 34.886 & 10.756 & $45 \%$ & 31.883 & -21.127 \\
\hline Borracha & 3.573 & 6.953 & 3.380 & $95 \%$ & 4.721 & -1.341 \\
\hline Frutas & 8.924 & 8.892 & -32 & $0 \%$ & 11.791 & -11.823 \\
\hline Mandioca & 1.414 & 1.060 & -354 & $-25 \%$ & 1.868 & -2.222 \\
\hline Outras Permanentes & 1.907 & 867 & -1.040 & $-55 \%$ & 2.520 & -3.560 \\
\hline Café & 3.506 & 798 & -2.708 & $-77 \%$ & 4.632 & -7.340 \\
\hline Outras temporárias & 5.014 & 667 & -4.347 & $-87 \%$ & 6.625 & -10.972 \\
\hline Sorgo & 6.183 & 1.620 & -4.563 & $-74 \%$ & 8.170 & -12.733 \\
\hline Feijão & 13.235 & 1.786 & -11.449 & $-87 \%$ & 17.487 & -28.936 \\
\hline Algodão & 21.950 & 458 & -21.492 & $-98 \%$ & 29.002 & -50.494 \\
\hline Milho & 134.250 & 48.267 & -85.983 & $-64 \%$ & 177.384 & -263.367 \\
\hline TOTAL & 517.720 & 1.201 .780 & 684.060 & $132 \%$ & 684.060 & 0 \\
\hline
\end{tabular}

Fonte: Os autores, a partir de dados do IBGE (2019a, b).

Considera-se que parte significativa desse incremento deu-se por meio da substituição de áreas de pastagens (atividade pecuária). No período analisado o rebanho bovino passou de 1,6 milhão de cabeças para 1 milhão, com decréscimo de cerca de 40\% (IBGE, 2019c).

Destaca-se o incremento significativo da cultura da cana-de-açúcar no período, passando de 287 mil para 1.075 mil hectares. Desse incremento, 380 mil ha devem-se à incorporação de novas áreas (Efeito Escala) e 407 mil ha pela substituição de áreas nas quais antes havia outras culturas (Efeito Substituição). Além da cana, outras culturas que tiveram aumento de áreas foram o amendoim, soja e a borracha (seringueira). Entre as culturas que mais perderam área estão: milho, algodão, feijão e sorgo.

No que se refere ao Efeito Substituição (Tabela 10), constatou-se que a cana-de-açúcar foi responsável por $98 \%$ da incorporação das áreas de outras culturas, observando-se que as culturas que mais cederam áreas foram: milho, algodão, feijão e soja. 
Tabela 10 - Efeito-substituição (ES) atribuído aos produtos que cederam área, em hectares, na Mesorregião São José do Rio Preto, entre 2003 e 2018

\begin{tabular}{|c|c|c|c|}
\hline \multirow{2}{*}{ Produtos que cederam área (ha) } & \multicolumn{3}{|c|}{-------- Produtos que incorporaram área (ha) ---------- } \\
\hline & Cana-de-açúcar & Amendoim & Total (ha) \\
\hline Borracha & 1.319 & 22 & 1.341 \\
\hline Mandioca & 2.186 & 37 & 2.222 \\
\hline Outras Permanentes & 3.501 & 59 & 3.560 \\
\hline Café & 7.220 & 121 & 7.340 \\
\hline Outras temporárias & 10.791 & 181 & 10.972 \\
\hline Frutas & 11.628 & 195 & 11.823 \\
\hline Sorgo & 12.523 & 210 & 12.733 \\
\hline Soja & 20.779 & 348 & 21.127 \\
\hline Feijão & 28.460 & 477 & 28.936 \\
\hline Algodão & 49.662 & 832 & 50.494 \\
\hline Milho & 259.027 & 4.340 & 263.367 \\
\hline TOTAL (ha) & 407.095 & 6.820 & 413.915 \\
\hline
\end{tabular}

\section{Região Oeste Paulista}

A partir das análises anteriores é possível avaliar a mudança do uso da terra na região Oeste Paulista como um todo (Tabela 11), entre 2003 e 2018. Nesse período houve aumento de aproximadamente 1,5 milhão de hectares da área agrícola nessa região, ou seja, um acréscimo de $72 \%$ da área.

Tabela 11 - Efeitos Escala (EE) e Substituição (ES) da região Oeste Paulista, entre 2003 e 2018

\begin{tabular}{|c|c|c|c|c|c|c|}
\hline \multirow{2}{*}{ Região Oeste Paulista } & \multicolumn{2}{|c|}{---Área cultivada (ha) --- } & \multicolumn{2}{|c|}{---Variação da Área--- } & \multirow{2}{*}{$\begin{array}{l}\text { EE } \\
\text { (ha) }\end{array}$} & \multirow{2}{*}{ (ha) ${ }^{\text {ES }}$} \\
\hline & 2003 & 2018 & (ha) & (\%) & & \\
\hline Cana-de-açúcar & 800.446 & 2.533 .127 & 1.732 .681 & $216 \%$ & 574.578 & 1.158 .103 \\
\hline Soja & 296.282 & 399.693 & 103.411 & $35 \%$ & 212.678 & -109.267 \\
\hline Borracha & 25.729 & 67.020 & 41.291 & $160 \%$ & 18.469 & 22.822 \\
\hline Amendoim & 34.924 & 76.117 & 41.193 & $118 \%$ & 25.069 & 16.124 \\
\hline Mandioca & 22.193 & 30.206 & 8.013 & $36 \%$ & 15.931 & -7.918 \\
\hline Batata-doce & 2.488 & 6.713 & 4.225 & $170 \%$ & 1.786 & 2.439 \\
\hline Urucum & 1.855 & 5.461 & 3.606 & $194 \%$ & 1.332 & 2.274 \\
\hline Outras temporárias & 27.639 & 22.845 & -4.794 & $-17 \%$ & 19.840 & -24.634 \\
\hline Outras permanentes & 32.549 & 27.040 & -5.509 & $-17 \%$ & 23.364 & -28.873 \\
\hline Arroz & 9.467 & 632 & -8.835 & $-93 \%$ & 6.796 & -15.631 \\
\hline Trigo & 24.550 & 2.897 & -21.653 & $-88 \%$ & 17.623 & -39.276 \\
\hline Algodão & 31.826 & 1.320 & -30.506 & $-96 \%$ & 22.845 & -53.351 \\
\hline Café & 88.726 & 51.499 & -37.227 & $-42 \%$ & 63.690 & -100.917 \\
\hline Feijão & 68.626 & 13.526 & -55.100 & $-80 \%$ & 49.261 & -104.361 \\
\hline Frutas & 166.446 & 64.665 & -101.781 & $-61 \%$ & 119.479 & -221.260 \\
\hline Milho & 513.756 & 386.267 & -127.489 & $-25 \%$ & 368.786 & -496.275 \\
\hline TOTAL & 2.147 .502 & 3.689 .028 & 1.541 .526 & $72 \%$ & 1.541 .526 & 0 \\
\hline
\end{tabular}

Fonte: Os autores, a partir de dados do IBGE (2019a, b). 
Considera-se, neste estudo, que parte significativa do incremento da área agrícola ocorreu por meio da substituição de áreas de pastagens anteriormente utilizadas na atividade pecuária. No período analisado o rebanho bovino passou de 8,4 milhões de cabeças para 5,9 miIhões, apresentando um decréscimo de cerca de 29\% (IBGE, 2019c).

Destaca-se o incremento significativo da cultura da cana-de-açúcar no período, passando de 800 mil para 2,5 milhões de hectares. Desse incremento, 574 mil ha devem-se à incorporação de novas áreas (Efeito Escala) e 1,1 milhão de ha, pela substituição de áreas nas quais antes havia outras culturas (Efeito Substituição).

Além da cana, outras culturas que tiveram aumento de áreas foram a soja, borracha (seringueira), amendoim, mandioca, batata-doce e o urucum. Entre as culturas que mais perderam área estão: milho, frutas, feijão, café, algodão, trigo e arroz.

No que se refere ao Efeito Substituição (Tabela 12), constatou-se que a cana-de-açúcar foi responsável por $96 \%$ da incorporação das áreas de outras culturas, observando-se que as culturas que mais cederam áreas foram: milho, frutas, soja, feijão, café, algodão e trigo.

Tabela 12 - Efeito-substituição (ES) atribuído aos produtos que cederam área, em hectares, na região Oeste Paulista, entre 2003 e 2018

\begin{tabular}{lrrrrrr}
\hline \multicolumn{1}{c}{$\begin{array}{c}\text { Produtos que } \\
\text { cederam área (ha) }\end{array}$} & Cana-de-açúcar & Borracha & Amendoim & Batata-doce & Urucum & Total (ha) \\
\hline Mandioca & 7.630 & 150 & 106 & 16 & 15 & 7.918 \\
Arroz & 15.063 & 297 & 210 & 32 & 30 & 15.631 \\
Outras temporárias & 23.739 & 468 & 331 & 50 & 47 & 24.634 \\
Outras permanentes & 27.824 & 548 & 387 & 59 & 55 & 28.873 \\
Trigo & 37.849 & 746 & 527 & 80 & 74 & 39.276 \\
Algodão & 51.413 & 1.013 & 716 & 108 & 101 & 53.351 \\
Café & 97.250 & 1.916 & 1.354 & 205 & 191 & 100.917 \\
Feijão & 100.570 & 1.982 & 1.400 & 212 & 198 & 104.361 \\
Soja & 105.297 & 2.075 & 1.466 & 222 & 207 & 109.267 \\
Frutas & 213.221 & 4.202 & 2.969 & 449 & 419 & 221.260 \\
Milho & 478.245 & 9.425 & 6.658 & 1.007 & 939 & 496.275 \\
\hline TOTAL (ha) & 1.158 .103 & 22.822 & 16.124 & 2.439 & 2.274 & 1.201 .762 \\
\hline
\end{tabular}

Fonte: Os autores, a partir de dados do IBGE (2019a, b).

\section{CONSIDERAÇÕES FINAIS}

Este artigo analisou as mudanças no uso da terra na Região Oeste Paulista, no período entre 2003 e 2018, provocadas pela expansão do setor sucroalcooleiro. Por meio do modelo de análise Shift-Share foi possível caracterizar a dinâmica de expansão da cana-de-açúcar, bem como analisar as alterações na composição agropecuária na região nos últimos 15 anos.

Os resultados mostraram um forte processo de expansão da área cultivada com cana-de-açúcar na região em análise, evidenciando o aumento da representatividade desta nos âmbitos estadual e nacional. 
Todas as mesorregiões analisadas que compõem o recorte geográfico deste estudo (Araçatuba, Assis, Marília, Presidente Prudente e São José do Rio Preto) apresentaram significativas expansões do cultivo da cana-de-açúcar, devido à disponibilidade de áreas e às condições edafoclimáticas adequadas.

Entre 2003 e 2018 tal região aumentou a área agrícola em 72\%, com variação de mais de 1,7 milhão de hectares. Nesse mesmo período o rebanho bovino da região foi reduzido em cerca de $30 \%$, ou 2,5 milhões de cabeças. Assim, pode-se afirmar que parte significativa do incremento da área agrícola ocorreu por meio da substituição de áreas de pastagens anteriormente utilizadas na atividade pecuária.

Além disso, analisando a dinâmica agrícola, pôde-se constatar uma evidente competição de áreas entre a cana-de-açúcar e as culturas já instaladas, como a borracha, amendoim, batata-doce e urucum, predominantemente característicos da região. Verificou-se que a expansão da cana-de-açúcar ocorreu, sobretudo, por meio da substituição de culturas agrícolas destinadas à produção de alimentos, como o milho, frutas, feijão, café, trigo e arroz.

Esses apontamentos, portanto, corroboram alguns estudos já referenciados neste artigo, no que diz respeito aos impactos socioambientais da expansão canavieira sobre as regiões produtoras, uma vez que, além da incorporação de áreas de pastagem (atividade pecuária bovina) e da substituição de áreas com commodities agrícolas, a expansão da cana-de-açúcar na Região Oeste Paulista também provocou a redução de áreas nas quais antes se cultivavam produtos característicos da cesta básica e/ou da pequena produção.

Por fim, considerando os possíveis impactos na estrutura fundiária, na atividade rural familiar, no preço da terra e na segurança alimentar local e regional, sugere-se, como agenda de trabalho, que outros estudos sejam realizados a fim de investigar os impactos ambientais, econômicos e sociais do processo de expansão da cana-de-açúcar na região.

\section{REFERÊNCIAS}

BARBOSA, R. R.; LUDWIG, M. P.; LORETO, M. D. S.; SOUSA. J. M. M. Histórico do setor sucroalcooleiro no Brasil: implantação de uma usina alcooleira em Bambuí-MG. SEMANA DE CIÊNCIA E TECNOLOGIA DO IFMG, 4., 2011. Bambuí, 2011.

CAMARA, M. R. G.; CALDARELLI, C. E. Expansão canavieira e o uso da terra no Estado de São Paulo. Estudos Avançados, São Paulo, v. 30, n. 88, p. 93-116, 2016.

CAMARGO, A. M. M. P.; CASER, D. V.; CAMARGO, F. P.; OlIVETTE, M. P. A.; SACHS, R. C. C.; TORQUATO, S. A. Dinâmica e tendência da cana-de-açúcar sobre as demais atividades agropecuárias. Informações Econômicas, São Paulo, v. 38, n. 3, p. 47-66, 2008.

CIDADE BRASIL. Mesorregiões do Brasil. Disponível em: https://www.cidade-brasil.com.br/mesorregiao. htm. Acesso em: 10 out. 2019.

CHEQUIN, B.; GRANDI, G. O setor sucroalcooleiro brasileiro: origem e desenvolvimento. CONFERÊNCIA INTERNACIONAL DE HISTÓRIA ECONÔMICA, 6., ENCONTRO DE PÓS-GRADUAÇÃO EM HISTÓRIA ECONÔMICA, 8., 2016, São Paulo/SP. Anais [...] São Paulo: Universidade de São Paulo, 2016.

DUFT, D. G.; PICOLI, M. C. A. Uso de imagens do sensor modis para identificação da seca na cana-de-açúcar através de índices espectrais. Revista Scientia Agraria. v. 19, n. 1, p. 52-63, 2018.

EISENBERG, P. L. Sugar industry in Pernambuco: modernization without change, 1840-1910. Berkeley: University of Califórnia Press, 1974.

EISENBERG, P. L. Modernização sem mudança: a indústria açucareira em Pernambuco. Campinas: Paz e Terra; Unicamp, 1977. 294 p. 
FAO. United Nations Food and Agriculture Organization. Biofuels and the sustainability challenge: a global assessment of sustainability issues, trends and policies for biofuels and related feedstocks. Trade and Market Division. Roma, 2013. 188 p.

FAO. United Nations Food and Agriculture Organization. Faostat. 2019. Disponível em: http://www.fao. org/faostat/en/\#data/QC. Acesso em: 17 nov. 2019.

GUIMARÃES, L. S. P. Dinâmica espacial da cana-de-açúcar no Brasil contemporâneo. In: IBGE. Evolução do espaço rural brasileiro. Rio de Janeiro: IBGE, 2016. p. 119-137.

GOES, T.; MARRA, R.; SILVA, G. S. Setor sucroalcooleiro no Brasil: situação atual e perspectivas. Revista Política Agrícola, a. XVII, n. 2, abr./maio/jun. 2008.

IBGE. Instituto Brasileiro de Geografia e Estatística. Divisão regional do Brasil em mesorregiões e microrregiões geográficas. 1990. Disponível em: https://biblioteca.ibge.gov.br/visualizacao/livros/liv2269_1.pdf. Acesso em: 16 dez. 2020.

IBGE. Instituto Brasileiro de Geografia e Estatística. Tabela 1612: área plantada, área colhida, quantidade produzida, rendimento médio e valor da produção das lavouras temporárias. 2019a. Disponível em: https://sidra.ibge.gov.br/tabela/1612. Acesso em: 20 set. 2019.

IBGE. Instituto Brasileiro de Geografia e Estatística. Tabela 1613: área plantada, área colhida, quantidade produzida, rendimento médio e valor da produção das lavouras permanentes. 2019b. Disponível em: https://sidra.ibge.gov.br/tabela/1613. Acesso em: 30 jan. 2020.

IBGE. Instituto Brasileiro de Geografia e Estatística. Tabela 3939: efetivo dos rebanhos, por tipo de rebanho. 2019c. Disponível em: https://sidra.ibge.gov.br/tabela/3939. Acesso em: 30 jan. 2020.

IBGE. Instituto Brasileiro de geografia e Estatística. IBGE Cidades: panorama. 2019d. Disponível em: https://cidades.ibge.gov.br/brasil/sp/panorama. Acesso em: 20 set. 2019.

IPEA. Instituto de Pesquisa Econômica Aplicada. Ipea Geo: Malhas. 2019. Disponível em: http://www. ipea.gov.br/ipeageo/malhas.html. Acesso em: 5 out. 2019.

KOHLHEPP, G. Análise da situação da produção de etanol e biodiesel no Brasil. Estudos Avançados. São Paulo, v. 24, n. 68, p. 223-253, 2010.

LEITE, R. C. C.; LEAL, M. R. L. V. O biocombustível no Brasil. Novos estudos - Cebrap, São Paulo, n. 78, p. 15-21, 2007.

LOURENZANI, W. L.; CALDAS, M. M. Mudanças no uso da terra decorrentes da expansão da cultura da cana-de-açúcar na região oeste do Estado de São Paulo. Ciência Rural, Santa Maria, v. 44, n. 11, p. 1.9801.987, 2014.

MICHELLON, E.; SANTOS, A. A. L.; RODRIGUES, J. R. A. Breve descrição do ProÁlcool e perspectivas futuras para o etanol produzido no Brasil. In: CONGRESSO DA SOCIEDADE BRASILEIRA DE ECONOMIA, ADMINISTRAÇÃO E SOCIOLOGIA RURAL, 26., 2008. Brasília. Anais [...]. Brasília, 2008.

NASS, L. L.; PEREIRA, P. A. A.; ELLIS, D. Biofuels in Brazil: an overview. Crop Science, v. 47, n. 6, p. $2.228-$ 2.237, 2007.

NOVACANA. As usinas de açúcar e etanol do Brasil. 2019. Disponível em: https://www.novacana.com/ usinas_brasil. Acesso em: 6 fev. 2020.

QUEDA, O. A intervenção do estado e a agroindústria açucareira paulista. 1972. Tese (Doutorado) ESALQ/USP, Piracicaba, 1972.

RAVAGNANI, R. M. Potenciais impactos no comércio internacional de biocombustiveis associados à implementação de esquemas de certificação. 2014. Dissertação (Mestrado) - Faculdade de Engenharia Mecânica, Universidade Estadual de Campinas, Campinas, 2014.

RFA. Renewable Fuels Association. World Fuel Ethanol Production. Disponível em: https://ethanolrfa.org/ resources/industry/statistics/\#1537559649968-e206480c-7160. Acesso em: 12 ago. 2019.

RUAS, D. G. G.; FERREIRA, E. R.; BRAY, S. C. A agroindústria sucroalcooleira nas áreas canavieiras de São Paulo e Paraná no Brasil. Rio Claro: Unesp/IGCE Pós-Graduação em Geografia, 2014.

SANTOS, F. A. A.; FARIA, R. A.; TEIXEIRA, E. C. Mudança da composição agrícola em duas regiões de Minas Gerais. Revista de Economia e Sociologia Rural, Brasília, v. 46, n. 3, p. 579-595, 2008.

SILVA, A.; MIZIARA, F. Avanço do setor sucroalcooleiro e expansão da fronteira agrícola em Goiás. Pesquisa Agropecuária Tropical, Goiânia, v. 41, n. 3, p. 399-407, 2011.

SLUZZ, T.; MACHADO, J. A. D. Características das potenciais culturas matérias-primas do biodiesel e sua adoção pela agricultura familiar. In: ENCONTRO DE ENERGIA NO MEIO RURAL, 6., 2006. Campinas, Proceedings on-line [...]. Campinas, 2006. 
TOLMASQUIM, M. T. Perspectivas e planejamento do setor energético no Brasil. Estudos Avançados, São Paulo, v. 26, n. 74, p. 247-260, 2012.

UNICA. União da Agroindústria Canavieira de São Paulo. 2019. Unicadata. Disponível em: https://www. unica.com.br/setor-sucroenergetico/acucar/. Acesso em: 9 jan. 2020.

USDA. United States Department of Agriculture. 2019. Sugar: World Markets and Trade. Disponível em: https://downloads.usda.library.cornell.edu/usda-esmis/files/z029p472x/r781wk715/nc580r03d/Sugar. pdf. Acesso em: 3 dez. 2019.

ZANZARINI, R. M.; SANTOS, R. J.; ALBINO, K. G. A expansão da cana-de-açúcar no Triângulo Mineiro: uma análise das alterações de cultivo no município de Araguari. Revista Tópos, Araguari: Universidade Federal de Uberlândia, v. 3, n. 2, 2008.

ZOCKUN, M. H. G. P. A expansão da soja no Brasil: alguns aspectos da produção. 1978. Dissertação (Mestrado) - USP; FEA, São Paulo, 1978. 